\title{
Over-Valuation: Avoid Double Counting when Retaining Dividends in the FCFE Valuation
}

\section{Understanding Discounted Cash Flow Valuation}

\author{
João Marques Silva ${ }^{1} \&$ José Azevedo Pereira $^{1}$ \\ ${ }^{1}$ Instituto Universitário de Lisboa (ISCTE-IUL), Lisbon, Portugal \\ Correspondence: João Marques Silva, Instituto Universitário de Lisboa (ISCTE-IUL), Lisbon, Portugal.
}

Received: July 18, 2017

doi:10.5430/ijfr.v8n4p107
Accepted: August 1, $2017 \quad$ Online Published: October 17, 2017

URL: https://doi.org/10.5430/ijfr.v8n4p107

\begin{abstract}
Valuation based on DCF (Discounted Cash Flow) has been the dominant valuation procedure during the last decades. In spite of this dominance, enterprise valuation using the discounted FCF (Free Cash Flow) model has some practical drawbacks, since there is often some confusion on how to effectively use it. Commonly, the valuation procedures start by estimating future FCF figures from historical data, such as mean FCF, growth and retention ratio, alongside many other variables. These FCF forecasts are discounted at the cost of equity (FCFE - FCF to Equity) or the Weighted Average Cost of Capital WACC (FCFF - FCF to Firm). Implicit in the above mentioned valuation procedures is the expectation that the company puts the retained free cash that is generating to good use, yielding a value capable of rewarding appropriately the level of risk inherent in the way it used. Some poorly performed valuation studies however tend to double count (Damodaran, 2006a) the retained cash's interest in subsequent values of FCF, or include the accumulated cash build-up in the Terminal Value. This paper discusses how these two common double-counting mistakes are made and evaluates their weight in the final valuation figure for the particular case of retained FCFE (the case for the FCFF is analogous, but we focus on FCFE for simplicity) using projected figures.
\end{abstract}

Keywords: valuation, free cash flow, discounted cash flow, reinvestment performance

\section{Introduction}

The essence of discounted cash flow valuation is simple; the asset is worth the expected cash flows it will generate, discounted to the reference date for the valuation exercise (normally, the day of the calculation). A survey article was written in Parker (1968), where it was stated that the earliest interest rate tables (use to discount value to the present) dated back to 1340 . However, financial mathematics can be traced to an earlier period - the writings of Fibonacci, in 1202. Later, in 1582, a Flemish mathematician, Simon Stevin wrote one of the first textbooks on finance, laying out the basis for calculating the present value in Stevin (1582). It was only after 3 centuries that a civil engineer, A.M. Wellington argued that the present value of future cash flows should be taken into account when calculating the up-front investment in Wellington (1887). The intellectual basis for discounted cash flow was described in both Bohm-Bawerk (1903) (with a home purchase example with 20 annual instalment payments) and Marshall (1907). Finally, present value equations were developed for annuities, in order to assess the need to either buy new equipment or retain old equipment in Pennell (1914).

The principles of modern valuation were consolidated in Irving Fisher's books (1907 and 1930). In these books, there were four alternative approaches for analyzing investments, namely choosing the investment that:

- had the highest present value at the market interest rate

- had the largest gap between benefits and cost in terms of present values

- had the highest "rate of return on sacrifice", above the market interest rate

- compared to the next most costly investment yielded a return in excess of the market rate

Note that the first two approaches represent the net present value rule, the third is the IRR - Internal Rate of Return approach and the last is the marginal rate of return approach. Later works from Boulding (1935) and Keynes (1936) 
derived the IRR for an investment. Samuelson (1937) compared the IRR and NPV (Net Present Value) approaches, arguing that rational investors should maximize NPV and not IRR.

The previously mentioned works and the publication of Joel Dean's reference book (Dean, 1951) on capital budgeting set the basis for the widespread use of the discounted cash flow approach into all business areas, aided by developments in portfolio theory. There are four main variants of discounted cash flow models, each with its own advantages and disadvantages. These are:

- Discounted cash flow with a risk-adjusted discount rate

- Certainty equivalent approach to valuation, where risk adjusted cash flows, termed certainty equivalent cash flows, are discounted at the risk-free rate;

- Adjusted Present Value (APV) approach, which consists of valuing a business without the effects of debt first, and then consider the effects of borrowing. This approach was first boarded by Modigliani and Miller (1963) with the isolation of the tax benefits from borrowing, but the APV in its current form was present in Myers (1974);

- Valuation based on excess returns on each investment.

In stock valuation, the dividend discount model was arguably first mentioned in Williams (1938), where the present value concept was connected to the stock's dividends. Williams also drew a distinction between valuing mature and growth companies in Williams (1938). The value of stock with perpetual growth was derived in Durand (1957), but it was Gordon who popularized the model in subsequent articles and a book, giving it the title of the Gordon growth model (Gordon, 1962). Due to the non-realistic property of a single perpetual dividend growth, the two stage (and multi-stage) model was devised in Bernstein (1967) - an extensive categorization of multi-stage models is provided in Damodaran (1994). The H model, a two stage growth model where the first stage has a linearly descending growth until the stable (constant) growth figure of the second stage, was devised in Fuller\&Hsia (1984).

The valuation of companies that pay no dividends due to reinvestment was analyzed in Michaud\&Davis (1981) (based on expected dividend payout when the growth rate declines). Fama\&French (1988) noted that dividend yields vary much more than dividends, and Foerster\&Sapp (2005) analyzed a long time period (from 1871 to 2003) and found that the dividend discount model does a good job explaining the main variations in the S\&P 500 index, though there were systematic differences over time in how investors valued future dividends.

The decline in the average level of dividends paid was analyzed in Fama\&French (2001), where it was concluded that today's market portfolio is mostly made of high growth firms and that firms became less likely to pay dividends, as dividend paying firms went from 66,5\% in 1978 to $20,8 \%$ in 1999. The work in DeAngelo et al (2004), Hoberg\&Prabhala (2005), Baker\&Wurgler (2004a) and Baker\&Wurgler (2004b) tried to explain the decline in dividends over time, attributing it to a variety of factors. The fact remained that the gap between dividends paid and potential dividends did increase over time, posing a challenge to the use of dividend discount models. The fix to the posed problem would be to replace dividends with potential dividends in the dividend discount model. Potential dividends can be estimated by three variants:

- Stock buyback as dividends: the work in Damodaran (2006b) presents the modified dividend payout including stock buybacks, and argues that it works well in explaining the market prices of companies that return cash over regular intervals via stock buybacks

- Free Cash Flow to Equity model: the publication of Hagstrom (2004) describes how Warren Buffet argued that investors should value companies based on its "owner's earnings", which were defined as the cash flows left after capital expenditures and working capital needs.

- Earnings Model: The model of discounting earnings or variants of earnings is discussed in Ohlson (1995) and Felthan \& Ohlson (1995), where a relationship between value and earnings is established. Penman \& Sougiannis (1997) argued that GAAP (Generally Accepted Accounting Principles) earnings could be substituted for dividends in equity valuation, as long as analysts would reduce future earnings and book value to reflect dividend payments. All these models were prone to double-counting (Penman \& Sougiannis (1997) described that "discounting earnings as if they were cash flows paid out to stockholders while also counting the growth that is created by reinvesting those earnings will lead to the systematic overvaluation of stocks"), something that was discussed in Glassman \& Hassett (2000).

Nowadays, probably the model with more widespread use is the FCFE / FCFF (Free Cash Flow to Equity and Free Cash Flow to Firm) model. For simplification purposes, we will focus on the FCFE model, which basically is the 
FCF model's version for the potential dividends. The question however of using potential dividends versus real dividends endures, and care must be taken in order not to double count cash flows (the main focus of this paper) and to assess what use is given to that excess cash flow - if it is invested wisely, what returns will come of them, how it is accounted for, etc (Damodaran, 2006b). The bridge to the FCFF model is straightforward; the FCFF includes FCFE and added cash that is owed to debt-holders.

The paper is structured as follows: in section 2 we discuss the need for the valuation correction factors and in section 3 we deduce them mathematically. Section 4 portrays some practical examples of the use of these factors, and Section 5 concludes.

\section{Need for Valuation Correction Factors}

In this section we will illustrate how discounted FCFE valuation can be misleading if not handled correctly. The yearly FCFE can be dealt with in many ways; it can be distributed as dividends (or stock buybacks); invested in a project or invested in the market (or even shelved) to provide liquidity for future events. All these options are valid, but when valuing a company based on projected FCFE, we need to make sure of what we are doing. Usually, many financial projections make some double counting mistakes that will raise the computed value of the company significantly. In this paper, we will analyze and correct the two most common mistakes.

When we consider growth from reinvesting the retained part of the FCFE, we must take care and account these earnings in a separate way; the FCFE must be calculated from operational income; the financial gains from reinvestments must not be included in the FCFE in order to avoid double counting. Note however that the shareholders expect to receive this money sooner or later, and while it's in the hands of the company, this money should render a rate of return that rewards appropriately the level of risk inherent to the way it is used, let's call it return on investment $r_{i}$. Since we discount FCFE at the cost of equity $r_{e}$, the earnings from retention of the FCFE (note that in this paper the retention ratio applies to the FCFE and not the net income, hence it is different than the retention ratio normally used in finance; the retention ratio of the FCFE implies that previously the company has retained the appropriate amount of capital to promote growth, via Capital Expenditure) that sometimes are incorrectly included in the following year's FCFE must be discounted also using $r_{e}$ as a discount factor. We will name this value Expected Earnings from Retention EER, in this paper, and use it to correct the error when incorrectly calculating the FCFE with financial gains from reinvestments.

Another common mistake is to include the cash build-up from retention in the terminal value, since the originating FCF were already discounted. Note that the cash build-up includes the financial gains from reinvestments, and thus this type of mistake is greater than the previous one. The corrective value for this mistake will be named Terminal Value Correction TVC in this paper.

We will analyze some scenarios, and assess the weight of each type of mistake. As main assumptions for this paper, we assume that the mean FCFE retention ratio $\mathrm{rr}_{\mathrm{FCFE}}$ from previous years will remain constant, and thus the payout ratio (usually in dividends) is maintained. The yearly FCFE is assumed to grow at a rate $\mathrm{g}_{\mathrm{FCFE}}$, the company's $\mathrm{rr}_{\mathrm{FCFE}}$ and $r_{e}$ are assumed to remain constant, and all investments with the retained capital are assumed to yield $r_{i}$. With these values in mind (initial FCFE, FCFE retention rate $\mathrm{rr}_{\mathrm{FCFE}}$, FCFE growth rate $\mathrm{g}_{\mathrm{FCFE}}$, investment return $r_{\mathrm{i}}$ and cost of equity $r_{e}$ ), we can effectively calculate the expected earnings (at rate $r_{i}$ ) alongside the subsequent cash build-up.

The EER and TVC will be discussed and mathematically deduced in the next section. The explanation for the EER and TVC are quite simple; the EER calculates all reinvestment gains from the retained part of the FCFE and discounts them to the present day (gains of $r_{i}$, discounted at $r_{e}$ ); the TVC equals the sum of the cash build-up (discounted at $r_{e}$ ) obtained from the retained earnings, that will add to the equity of the company.

\section{Derivation of the Correction Factors}

The correction factors are discussed and derived in this section. For valuation purposes, usually an annuity is used, with a calculated FCFE as an initial value, a mean FCFE retention rate $\mathrm{rr}_{\mathrm{FCFE}}$ and an estimated growth rate $\mathrm{g}_{\mathrm{FCFE}}$. We don't know what the company will do with the FCFE (usually having a great amount of cash available might make managers want to allocate some of it for futile expenses or overpay for an investment), but we can calculate the shareholder's expectations on the return from that FCFE, assuming that the money is effectively invested on the market, and getting a return equivalent to the investment's risk $r_{i}$ (note that the shareholder's overall expected return on their invested capital is $r_{e}$, which is usually bigger than the market's return $r_{m}$ if the company has a beta>1 compared to the market).

Before deriving the equations for EER and TVC, it's useful to remember that an annuity with growth $\mathrm{g}$ discounted at rate $r$ is calculated as ( $\mathrm{P}$ is the initial value): 


$$
A=\frac{P}{r-g}\left[1-\left(\frac{1+g}{1+r}\right)^{n}\right]
$$

In the case of $\mathrm{r}=\mathrm{g}$, we have $A=\sum_{i=1}^{n} \frac{P}{1+r}=\frac{n P}{1+r}$

Another formula of interest is the sum of a geometric series that is given by

$$
A=\sum_{t=0}^{n-1} a r^{t}=a\left(\frac{1-r^{n}}{1-r}\right)
$$

Let us define DICYF as the Discounted Interest from Current Year's FCFE, which represents the total interest that the withheld FCFE in year $t$ will yield up until year $n$, discounted to year $t$ at $r_{e}$, when used in an application that renders $r_{i}$ interest. Using equation (1) we arrive at:

$$
\operatorname{DICYF}\left(r_{e}, r_{i}, n, t\right)=\frac{r r_{F C F E} \times \mathrm{r}_{\mathrm{i}} \times \mathrm{FCFE}_{\mathrm{t}}}{\mathrm{r}_{\mathrm{e}}-r_{i}} \times\left[1-\left(\frac{1+r_{i}}{1+\mathrm{r}_{\mathrm{e}}}\right)^{n-t}\right]
$$

If $r_{e}=r_{i}$, then we can rewrite it as:

$$
\operatorname{DICYF}\left(r_{e}, n, t\right)=\frac{(n-t) \times r r_{F C F E} \times \mathrm{r}_{\mathrm{e}} \times \mathrm{FCFE}_{\mathrm{t}}}{1+\mathrm{r}_{\mathrm{e}}}
$$

With

$$
\mathrm{FCFE}_{\mathrm{t}}=\mathrm{FCFE}_{1} \times\left(1+g_{F C F E}\right)^{t-1}
$$

(e.g. with $\mathrm{FCFE}=100, \mathrm{r}_{\mathrm{e}}=\mathrm{r}_{\mathrm{i}}=10 \%, \mathrm{rr}_{\mathrm{FCFE}}=100 \%$ and $\mathrm{n}-\mathrm{t}=2$, we would have $D I C Y F=\frac{10}{1,1}+\frac{11}{1,1^{2}}=2 \times \frac{10}{1,1}=18,2$ ).

To compute the EER, we have (for the case $r_{e}=r_{i}$ ):

$$
\begin{aligned}
E E R\left(r_{e}, n, t\right)=\sum_{t=1}^{n-1} & \frac{D I C Y F\left(r_{e}, n, t\right)}{\left(1+r_{e}\right)^{t}} \\
& =\sum_{t=1}^{n-1} \frac{(n-t) \times r r_{F C F E} \times \mathrm{r}_{\mathrm{e}} \times \mathrm{FCFE}_{\mathrm{t}}}{\left(1+r_{e}\right)^{t+1}}==\sum_{t=1}^{n-1} \frac{(n-t) \times r r_{F C F E} \times \mathrm{r}_{\mathrm{e}} \times \mathrm{FCFE}_{1} \times\left(1+g_{F C F E}\right)^{t-1}}{\left(1+r_{e}\right)^{t+1}} \\
& =r r_{F C F E} \times \mathrm{r}_{\mathrm{e}} \times \mathrm{FCFE}_{1} \times \sum_{t=1}^{n-1} \frac{(n-t) \times\left(1+g_{F C F E}\right)^{t-1}}{\left(1+r_{e}\right)^{t+1}}
\end{aligned}
$$

Or in the case that $\left(r_{\mathrm{e}} \neq \mathrm{r}_{\mathrm{i}}\right)$ :

$$
\begin{gathered}
\operatorname{EER}\left(r_{e}, r_{i}, n, t\right)=\sum_{t=1}^{n-1} \frac{\operatorname{DICYF}\left(r_{e}, r_{i}, n, t\right)}{\left(1+r_{e}\right)^{t}}=\frac{r r_{F C F E} \times \mathrm{r}_{\mathrm{i}} \times \mathrm{FCFE}_{1}}{\mathrm{r}_{\mathrm{e}}-r_{i}} \times \sum_{t=1}^{n-1}\left[\left(1+g_{F C F E}\right)^{t-1} \times \frac{\left.1-\left(\frac{1+r_{i}}{1+\mathrm{r}_{\mathrm{e}}}\right)^{n-t}\right]}{\left(1+r_{e}\right)^{t}}\right] \\
=\frac{r r_{F C F E} \times \mathrm{r}_{\mathrm{i}} \times \mathrm{FCFE}_{1}}{\left(1+\mathrm{r}_{\mathrm{e}}\right)^{n}} \times \sum_{t=1}^{n-1}\left[\left(1+g_{F C F E}\right)^{t-1} \times \frac{1-\left(1+\mathrm{r}_{\mathrm{i}}\right)^{n-t}}{1-\left(1+\mathrm{r}_{\mathrm{i}}\right)}\right]
\end{gathered}
$$

The TVC is calculated as (through the use of equation (2) and the reasoning in EER):

$$
\begin{aligned}
T V C\left(r_{e}, r_{i}, n, t\right)= & r r_{F C F E} \times \mathrm{FCFE}_{1} \times\left(\frac{\left(\frac{1-\left(1+g_{F C F E}\right)^{n}}{1-\left(1+g_{F C F E}\right)}\right)+\mathrm{r}_{\mathrm{i}} \times \sum_{t=1}^{n-1}\left[\left(1+g_{F C F E}\right)^{t-1} \times \frac{1-\left(1+\mathrm{r}_{\mathrm{i}}\right)^{n-t}}{1-\left(1+\mathrm{r}_{\mathrm{i}}\right)}\right]}{\left(1+\mathrm{r}_{\mathrm{e}}\right)^{n}}\right) \\
& =r r_{F C F E} \times \mathrm{FCFE}_{1} \times\left(\frac{\left(\frac{-1+\left(1+g_{F C F E}\right)^{n}}{g_{F C F E}}\right)+\sum_{t=1}^{n-1}\left[\left(1+g_{F C F E}\right)^{t-1} \times\left(\left(1+\mathrm{r}_{\mathrm{i}}\right)^{n-t}-1\right)\right]}{\left(1+\mathrm{r}_{\mathrm{e}}\right)^{n}}\right)
\end{aligned}
$$

If $g_{F C F E}=0$, we have

$$
T V C=r r_{F C F E} \times \mathrm{FCFE}_{1} \times\left(\frac{n+\sum_{t=1}^{n-1}\left(1+\mathrm{r}_{\mathrm{i}}\right)^{n-t}}{\left(1+\mathrm{r}_{\mathrm{e}}\right)^{n}}\right)
$$

And if $r_{i}=0 \%$ (same as shelving the retained capital), we have: 


$$
T V C=r r_{F C F E} \times \mathrm{FCFE}_{1} \times\left(\frac{\left(1+g_{F C F E}\right)^{n}-1}{g_{F C F E}\left(1+\mathrm{r}_{\mathrm{e}}\right)^{n}}\right)
$$

If we wanted to derive the formulas for FCFF, we would use the WACC instead of $r_{e}$, and the retention rate would apply to the whole of FCFF.

\section{Pratical Examples}

In this section we will look at 5 different cases (depicted in table 1), each with different return on investment $\mathrm{r}_{\mathrm{i}}$, FCFE retention ratio $\mathrm{rr}_{\mathrm{FCFE}}$ and $\mathrm{FCFE}$ growth $\mathrm{g}_{\mathrm{FCFE}}$. All scenarios cover $\mathrm{n}=5$ years, and assume an initial equity investment of $1000 €$ and a return on equity equivalent (for simplicity) to the cost of equity $\mathrm{r}_{\mathrm{e}}$ equal to $10 \%$, meaning that the FCFE of the first year will be $10 \%$ of $1000 €=100 €$. At the end of the $5^{\text {th }}$ year, we assume that we will be able to sell the business by the same amount as the initial investment of $1000 €$ (let's assume a terminal value of $1000 €$ ).

Cases A, B and D have $\mathrm{g}_{\mathrm{FCFE}}=0 \%$, meaning that their valuation based on discounted FCFE will yield $1000 €$. Cases $\mathrm{C}$, $\mathrm{E}$ and $\mathrm{F}$ have positive FCFE growth of 5\%, and thus yield a valuation of 1035,98€. For all cases, we will describe the two most common mistakes in valuation, namely the wrong FCFE using reinvestment gains (corrected by the EER) and the incorrect use of the cash build-up (corrected by the TVC).

Table 1. Case scenarios

\begin{tabular}{|c|cccccc|}
\hline Case & A & B & C & D & E & F \\
\hline ri & $10 \%$ & $10 \%$ & $10 \%$ & $5 \%$ & $5 \%$ & $0 \%$ \\
RRFCFE & $100 \%$ & $50 \%$ & $100 \%$ & $100 \%$ & $100 \%$ & $100 \%$ \\
gfcfe & $0 \%$ & $0 \%$ & $5 \%$ & $0 \%$ & $5 \%$ & $5 \%$ \\
\hline
\end{tabular}

Case A - Figure 1 depicts the situation for this case. Note that the real valuation figure for this case is $1000 €$ (FCFEs of $100 €$ discounted at re each year, added to the discounted terminal value of $1000 €$ in the final year). The valuation based on the wrong (double counted) FCFE yields 1075,47€ (thus the correction factor EER is $75,47 €$, which accounts for the investment interest discounted at $\mathrm{r}_{\mathrm{e}}$, yielding the valuation value of $1075,47 €-75,47 €=1000 €$ ), and the valuation based on the wrong terminal value yields $1379,08 €$ (the correction factor TVC is thus $379,08 €$; which is the total cash build-up of $610,50 €$ discounted at $r_{e}$ ). Note from this example, that the wrong terminal value is the correct terminal value with the cash build-up added to it (and thus the need for TVC), and that the wrong FCFE has the gained financial interest added to it (and thus the need for EER).

\begin{tabular}{|l|rrrrr|}
\cline { 2 - 7 } \multicolumn{1}{c|}{} & \multicolumn{1}{c}{ Year 1 } & Year 2 & Year 3 & Year 4 & Year 5 \\
\hline Real FCFE & 100,0 & 100,0 & 100,0 & 100,0 & 100,0 \\
Dividends & 0,0 & 0,0 & 0,0 & 0,0 & 0,0 \\
Retained Earnings & 100,0 & 100,0 & 100,0 & 100,0 & 100,0 \\
Cash Build-up & 100,0 & 210,0 & 331,0 & 464,1 & 610,5 \\
Yearly Interest & 0,0 & 10,0 & 21,0 & 33,1 & 46,4 \\
Wrongfully Used FCFE & 100,0 & 110,0 & 121,0 & 133,1 & 146,4 \\
\hline Terminal Value & & & & & 1000,0 \\
Wrongfully Used Terminal Value & & & & & 1610,5 \\
\hline
\end{tabular}

Figure 1. Example: case A

Case B differs from case A due to its $\mathrm{rr}_{\mathrm{FCFE}}$ of $50 \%$. The firm will invest $50 \%$ of the FCFE and distribute the rest as dividends. The real valuation remains $1000 €$, but the wrong valuation figures are now smaller than in case $\mathrm{A}$, since the cash build-up is smaller and the gained interest are $10 \%$ of $50 \%$ of the FCFE and not $10 \%$ of $100 \%$ of the FCFE. The EER is $37,73 €$ and the TVC is $189,54 €$ (wrong valuation figures of $1037,73 €$ and $1189,54 €$ respectively).

\begin{tabular}{|l|rrrrr|}
\cline { 2 - 6 } \multicolumn{1}{c|}{} & \multicolumn{1}{c}{ Year 1 } & Year 2 & Year 3 & Year 4 & Year 5 \\
\hline Real FCFE & 100,0 & 100,0 & 100,0 & 100,0 & 100,0 \\
Dividends & 50,0 & 50,0 & 50,0 & 50,0 & 50,0 \\
Retained Earnings & 50,0 & 50,0 & 50,0 & 50,0 & 50,0 \\
Cash Build-up & 50,0 & 105,0 & 165,5 & 232,1 & 305,3 \\
Yearly Interest & 0,0 & 5,0 & 10,5 & 16,6 & 23,2 \\
Wrongfully Used FCFE & 100,0 & 105,0 & 110,5 & 116,6 & 123,2 \\
\hline Terminal Value & & & & & 1000,0 \\
Wrongfully Used Terminal Value & & & & & 1305,3 \\
\hline
\end{tabular}

Figure 2. Example: case B 
Case $\mathrm{C}$ differs from case $\mathrm{A}$ due to a $\mathrm{g}_{\mathrm{FCFE}}$ of $5 \%$, yielding a real valuation level of $1035,98 €$ Since the cash build-up is now higher, the double counting effect will be stronger. The correction factors yield an EER of 78,97€ (for a wrong valuation value of $1035,98 €+78,97 €$ ) and TVC of $415,06 €$ (for a wrong valuation factor of $1035,98 €+415,06 €$ ).

\begin{tabular}{|l|rrrrrr|}
\cline { 2 - 7 } \multicolumn{1}{c|}{} & \multicolumn{1}{c}{ Year 1 } & Year 2 & Year 3 & Year 4 & Year 5 \\
\hline Real FCFE & 100,0 & 105,0 & 110,3 & 115,8 & 121,6 \\
Dividends & 0,0 & 0,0 & 0,0 & 0,0 & 0,0 \\
Retained Earnings & 100,0 & 105,0 & 110,3 & 115,8 & 121,6 \\
Cash Build-up & 100,0 & 215,0 & 346,8 & 497,2 & 668,5 \\
Yearly Interest & 0,0 & 10,0 & 21,5 & 34,7 & 49,7 \\
Wrongfully Used FCFE & 100,0 & 115,0 & 131,8 & 150,4 & 171,3 \\
\hline Terminal Value & & & & & 1000,0 \\
Wrongfully Used Terminal Value & & & & & 1668,5 \\
\hline
\end{tabular}

Figure 3. Example: case $\mathrm{C}$

Case D differs from case A due to the return on investment $\mathrm{r}_{\mathrm{i}}$, which is now 5\% instead of $10 \%$ (real valuation remains $1000 €$ ). This means that the capital the company retains now yields only $5 \%$ instead of $10 \%$, meaning a smaller cash build-up. The EER is now $35,98 €$ (earnings now only at $5 \%$; so practically half of case A) and the TVC yields $343,10 €$.

\begin{tabular}{|l|rrrrr|}
\cline { 2 - 7 } \multicolumn{1}{c|}{} & \multicolumn{1}{c}{ Year 1 } & Year 2 & Year 3 & Year 4 & Year 5 \\
\hline Real FCFE & 100,0 & 100,0 & 100,0 & 100,0 & 100,0 \\
Dividends & 0,0 & 0,0 & 0,0 & 0,0 & 0,0 \\
Retained Earnings & 100,0 & 100,0 & 100,0 & 100,0 & 100,0 \\
Cash Build-up & 100,0 & 205,0 & 315,3 & 431,0 & 552,6 \\
Yearly Interest & 0,0 & 5,0 & 10,3 & 15,8 & 21,6 \\
Wrongfully Used FCFE & 100,0 & 105,0 & 110,3 & 115,8 & 121,6 \\
\hline Terminal Value & & & & & 1000,0 \\
Wrongfully Used Terminal Value & & & & & 1552,6 \\
\hline
\end{tabular}

Figure 4. Example: case D

Case $\mathrm{E}$ has a $\mathrm{r}_{\mathrm{i}}$ and $\mathrm{g}_{\mathrm{FCFE}}$ of $5 \%$ (real valuation equal to case $\mathrm{C}$ ). Due to the growth of the FCFE, the EER and TVC are slightly higher than in case $\mathrm{D}(37,69 €$ and $377,37 €$ respectively).

\begin{tabular}{|l|rrrrr|}
\cline { 2 - 6 } \multicolumn{1}{c|}{} & \multicolumn{1}{c}{ Year 1 } & Year 2 & Year 3 & Year 4 & Year 5 \\
\hline Real FCFE & 100,0 & 105,0 & 110,3 & 115,8 & 121,6 \\
Dividends & 0,0 & 0,0 & 0,0 & 0,0 & 0,0 \\
Retained Earnings & 100,0 & 105,0 & 110,3 & 115,8 & 121,6 \\
Cash Build-up & 100,0 & 210,0 & 330,8 & 463,1 & 607,8 \\
Yearly Interest & 0,0 & 5,0 & 10,5 & 16,5 & 23,2 \\
Wrongfully Used FCFE & 100,0 & 110,0 & 120,8 & 132,3 & 144,7 \\
\hline Terminal Value & & & & & 1000,0 \\
Wrongfully Used Terminal Value & & & & & 1607,8 \\
\hline
\end{tabular}

Figure 5. Example: case E

To finalize, case $\mathrm{F}$ has a $\mathrm{g}_{\mathrm{FCFE}}$ of $5 \%$ (real valuation equal to case $\mathrm{C}$ ), $\mathrm{rr}_{\mathrm{FCFE}}$ of $100 \%$ and a $\mathrm{r}_{\mathrm{i}}$ of $0 \%$, meaning that although the company is increasing its FCFE and not distributing dividends, no gains are being obtained to the retained capital (it's being literally "shelved"). So being, the EER is $0 €$, and the only correction factor to take into account is the TVC of $343,10 €$, correcting the (wrong) valuation of $1379,08 €$ to $1035,98 €$.

\begin{tabular}{|l|rrrrrr|}
\cline { 2 - 7 } \multicolumn{1}{c|}{} & \multicolumn{1}{c|}{ Year 1 } & Year 2 & Year 3 & Year 4 & Year 5 \\
\hline Real FCFE & 100,0 & 105,0 & 110,3 & 115,8 & 121,6 \\
Dividends & 0,0 & 0,0 & 0,0 & 0,0 & 0,0 \\
Retained Earnings & 100,0 & 105,0 & 110,3 & 115,8 & 121,6 \\
Cash Build-up & 100,0 & 205,0 & 315,3 & 431,0 & 552,6 \\
Yearly Interest & 0,0 & 0,0 & 0,0 & 0,0 & 0,0 \\
Wrongfully Used FCFE & 100,0 & 105,0 & 110,3 & 115,8 & 121,6 \\
\hline Terminal Value & & & & & 1000,0 \\
Wrongfully Used Terminal Value & & & & & 1552,6 \\
\hline
\end{tabular}

Figure 6. Example: case F 
To assess the weight and impact of the correction factors, table 2 was drawn, where each correction factor is divided by the real valuation value. Notice that the TVC ranges from $19 \%$ to $40 \%$ of the real valuation level (basically measuring the cash build-up level) and that the EER ranges from $0 \%$ to 7,6\%. Both correction factors show by how much a company may be over-valued when double counting each of this wrong procedures.

Table 2. Weight of the correction factors

\begin{tabular}{|c|cccccc|}
\hline Case & A & B & C & D & E & F \\
\hline EER/Valuation & $7,5 \%$ & $3,8 \%$ & $7,6 \%$ & $3,6 \%$ & $3,6 \%$ & $0,0 \%$ \\
TVC/Valuation & $37,9 \%$ & $19,0 \%$ & $40,0 \%$ & $34,3 \%$ & $36,4 \%$ & $33,1 \%$ \\
\hline
\end{tabular}

To summarise, in this paper we calculated what adjustments can be made to wrongfully used FCFE and terminal values, as well as estimating their impact weight on the firm's valuation. We could assess that over-valuation values could range from $0 \%$ to $40 \%$, distorting the real value with severe financial consequences.

\section{Conclusion}

With the explained correction factors, we can correct overvaluation from FCF (the paper particularized for FCFE) that are retained by the company. In fact, when projecting FCF results, double counting is usually present when taking into account growth (from reinvestments' yields) or terminal value calculations (FCF accounted for in their corresponding years shouldn't influence the terminal value). Using the correction factors to correct either wrong FCFE or terminal value estimates will remove double counting, and thus allow for analysts to perform correct valuation estimates.

\section{Acknowledgements}

We gratefully acknowledge financial support from FCT- Fundação para a Ciencia e Tecnologia (Portugal), national funding through research grant (UID/SOC/04521/2013).

\section{References}

Aswath Damodaran. (2006a). Damodaran on Valuation: Security Analysis for Investment and Corporate Finance (2nd ed.). John Wiley \& Sons, Inc.

Baker, M., \& J. Wurgler. (2004a). Appearing and disappearing dividends: The link to catering incentives. Journal of Financial Economics, 73, 271-288. https://doi.org/10.1016/j.jfineco.2003.08.001

Baker, M., \& J. Wurgler. (2004b). A catering theory of dividends. Journal of Finance, 59, 1125-1165. https://doi.org/10.1111/j.1540-6261.2004.00658.x

Bernstein. (1967). Proprietary two-stage dividend discount model used by the investment firm Sanford Bernstein.

Bohm-Bawerk, A.V. (1903). Recent Literature on Interest. Macmillan.

Boulding, K.E. (1935). The Theory of a Single Investment. Quarterly Journal of Economics, 49, 479-494. https://doi.org/10.2307/1883864

Damodaran, A. (1994). Damodaran on Valuation. John Wiley, New York.

Damodaran, A. (2006b). Damodaran on Valuation (2nd ed.). John Wiley and Sons, New York.

Dean, Joel. (1951). Capital Budgeting. Columbia University Press, New York.

DeAngelo, H., L. DeAngelo, \& D. Skinner. (2004). Are dividends disappearing? Dividend concentration and the consolidation of earnings. Journal of Financial Economics, 72, 425-456. https://doi.org/10.1016/S0304-405X(03)00186-7

Durand D. (1957). Growth Stcks and the St. Petersburg Paradox. Journal do Finance, 12, 348-363.

Fama, E., \& K. French. (1988). Dividend Yields and Expected Stock Returns. Journal of Financial Economics, 22, 3-25. https://doi.org/10.1016/0304-405X(88)90020-7

Fama, E.F., \& K. R. French. (2001). Disappearing dividends: Changing firm characteristics or lower propensity to pay?. Journal of Financial Economics, 60, 3-44. https://doi.org/10.1016/S0304-405X(01)00038-1

Feltham, G., \& J. Ohlson. (1995). Valuation and Clean Surplus Accounting of Operation and Financial Activities. Contemporary Accounting Research, 11, 689-731. https://doi.org/10.1111/j.1911-3846.1995.tb00462.x

Fisher I. (1907). The Rate of Interest. Macmillan, New York. 
Fisher I. (1930). The Theory of Interest. Macmillan, New York.

Foerster, S.R., \& S.G, Sapp. (2005). Dividends and Stock Valuation: A study of the Nineteenth to the Twenty-first Century. Working Paper, University of Western Ontario.

Fuller R.J., \& C. Hsia. (1984). A Simplified Common Stock Valuation Model. Financial Analysts Journal, 40, 49-56. https://doi.org/10.2469/faj.v40.n5.49

Glassman, J., \& K. Hassett. (2000). Dow 36,000: The New Strategy for Profiting from the Coming Rise in the Stock Market. Three Rivers Press.

Gordon, M.J. (1962). The Investment, Financing and Valuation of the Corporation. Homewood, Illinois: Richard D. Irwin Inc.

Hagstrom, R. (2004). The Warren Buffett Way. John Wiley, New York.

Hoberg, G., \& N.R. Prabhala. (2005). Disappearing Dividends: The Importance of idiosyncratic risk and the irrelevance of catering. Working paper, University of Maryland.

Keynes, J. M. (1936). The General Theory of Employment. Macmillan, London.

Marshall A. (1907). Principles of Economics. Macmilllan, London.

Michaud, R.O., \& P.L. Davis. (1981). Valuation Model Bias and the Scale Structure of Dividend Discount Returns. Journal of Finance, 37, 565-573.

Modigliani, F., \& M. Miller. (1963). Corporate Income Taxes and the Cost of Capital: A Correction. American Economic Review, 53, 433-443.

Myers, S. (1974). Interactions in Corporate Financing and Investment Decisions-Implications for Capital Budgeting. Journal of Finance, 29, 1-25. https://doi.org/10.1111/j.1540-6261.1974.tb00021.x

Ohlson J. (1995). Earnings, Book values and Dividends in Security Valuation. Contemporary Accounting Research, 11, 661-687. https://doi.org/10.1111/j.1911-3846.1995.tb00461.x

Parker, R.H. (1968). Discounted Cash Flow in Historical Perspective. Journal of Accounting Research, 6, 58-71. https://doi.org/10.2307/2490123

Penman, S., \& T. Sougiannis. (1997). The Dividend Displacement Property and the Substitution of Anticipated Earnings for Dividends in Equity Valuation. The Accounting Review, 72, 1-21.

Pennell, W.O. (1914). Present Worth Calculations in Engineering Studies. Journal of the Association of Engineering Societies.

Samuelson, P. (1937). Some Aspects of the Pure Theory of Capital. Quarterly Journal of Economics, 51, 469-496. https://doi.org/10.2307/1884837

Stevin S. (1582). Tables of Interest.

Wellington, A.M. (1887). The Economic Theory if the Location of Railways. Wiley, New York.

Williams, J.B. (1938). Theory of Investment Value. Fraser Publishing. 